\title{
A genetic study of Duchenne muscular dystrophy in the West Midlands
}

\author{
SARAH BUNDEY \\ From the Department of Clinical Genetics, Infant Development Unit, Queen Elizabeth Medical Centre, \\ Birmingham B15 2TG
}

SUMMARY A study of Duchenne muscular dystrophy has shown an approximate prevalence of the disease among schoolboys to be 1 in 4000 . Fifty-four families were available for genetic studies. In 19 families there were further affected cases and in 34 families the index patient was an isolated case. The proportion of affected brothers was 0.22 (11 of 50). There were 142 female relatives who had a risk of 1 in 10 or worse of being carriers; 66 of these were aged under 16. As genetic counselling is being increasingly requested by these families, an expansion of genetic services is envisaged. A genetic register, with frequent contact with families by ancillary staff, similar to that in Edinburgh, is considered desirable for the West Midlands.

Duchenne muscular dystrophy is a progressive $\mathrm{X}$ linked disorder in which affected males almost always die before reproducing. In spite of this lethality, the condition is remarkably common affecting about one boy in $3000,{ }^{1}$ suggesting that the mechanism producing a mutation is unusual. Another intriguing feature is that all series of patients who have been selected on account of their disease only, and not because of a known family history, show that most cases are isolated (table 1). This observation suggests that mutation is more common in females than in males.

The present study had several aims. The first was to calculate the incidence of Duchenne muscular dystrophy within the city of Birmingham. The second was to evaluate the use of creatine kinase levels measured by local laboratories in the assessment of female carriers, and also to assess whether physical Received for publication 2 April 1980 examination or measurement of haemopexin levels were useful in carrier detection. The third aim was to use segregation ratios and carrier detection tests to determine what proportion of mothers of index patients were new mutations, and from this to calculate the a priori risk of the mother of an isolated case being a carrier. The fourth aim was to assess any effect of parental age in those cases thought to be the result of new mutations. The final aim was to assess what use had been made of genetic counselling in the past and whether a more active approach, such as through the use of a genetic register, was required for the future.

\section{Methods}

Ascertainment of the patients in the study took place over two years from January 1975 to December 1976. All paediatricians under the West Midlands

TABLE 1 Proportion of affected brothers of index patients in seven population studies of Duchenne muscular dystrophy

\begin{tabular}{lccc}
\hline Study & No of index patients & Affected brothers/total brothers & Proportion of affected brothers \\
\hline Stephens and Tyler ${ }^{2}$ & 33 & $6 / 44$ & $0 \cdot 14$ \\
Stevenson ${ }^{3}$ & 33 & $10 / 48$ & $0 \cdot 21$ \\
Blyth and Pugh & 55 & $13 / 63$ & $0 \cdot 21$ \\
Gardner-Medwin 1 & 77 & $23 / 77 *$ & $0 \cdot 30$ \\
Thompson and Huttons & 129 & $40 / 165$ & $0 \cdot 24$ \\
Zatz et al & 146 & $65 / 231$ & $0 \cdot 28$ \\
Present study & 54 & $11 / 49$ & $0 \cdot 22$ \\
Total & 527 & $168 / 670$ & $0 \cdot 25$ \\
\hline
\end{tabular}

*Estimated total, assuming one brother per index patient. 
Regional Health Authority were written to and asked for the names of patients with Duchenne muscular dystrophy. In this way 36 names were obtained. Other sources of patients were: the in-patient diagnostic index of The Children's Hospital, Birmingham (18 patients); the diagnostic index of the Genetic Advisory Service of the West Midlands (16 patients); neurologists in Birmingham (8 patients); and the Birmingham Area Health Authority for the names of boys attending physically handicapped schools within the city (19 patients). A total of 74 names was obtained, 23 patients being ascertained more than once. Of these boys, 20 were not included in the study on account of (1) a request by the consultant or general practitioner not to visit the family (5 patients); (2) the family's refusal to co-operate (6 patients); (3) the patient and family could not be traced (6 patients); and (4) the family was unavailable because of death or moving out of the area (3 patients). This left 54 patients for inclusion in the study.

The 45 index patients who were alive were reexamined to confirm the diagnosis, to assess the extent and progression of their muscle weakness, and to see whether mental retardation was evident. The criteria for diagnosis were that the patient was male, had proximal weakness of characteristic distribution and large calves, had such rapid progression of signs that he was, or was likely to be, chairbound by the age of 12 , and had an early level of creatine kinase over 2000 units. Perusal of the medical records of the nine index patients who had died left no doubt that they too had had Duchenne muscular dystrophy.

The $\mathbf{5 4}$ families were visited and a family history taken from their mothers. Any relative with a history suggestive of muscular dystrophy was examined if alive, otherwise medical records were obtained. An attempt was made to see all sisters of patients and any maternal aunts and maternal grandmothers who were available. These female relatives were questioned about symptoms of muscle weakness, examined for evidence of limb girdle weakness or calf hypertrophy, and had blood taken for haemopexin and creatine kinase estimations.

At least one week later a second specimen of blood for creatine kinase level was taken by the general practitioner and returned by post. The blood was then separated and the serum divided into two. One sample was delivered to the Clinical Chemistry Department at the Midland Centre for Neurosurgery and Neurology (MCNN) where it was stored at $4^{\circ} \mathrm{C}$ before being analysed within a week. The other sample was analysed at the Queen Elizabeth Medical Centre (QEMC), mostly within a few days, but some of the early QEMC samples were frozen and analysed later because the method of analysis changed during 1975.

Creatine kinase $(\mathrm{CK})$ was measured in the two laboratories by different methods ${ }^{7}$ and the levels were compared to those for appropriately aged controls. ${ }^{7}$ Haemopexin assays were carried out using Behringwerke M-partigen plates containing haemopexin antiserum. Protein from the sample sera diffuses out from punched holes and precipitates with the antiserum. The diameter of the ring of precipitation is directly related to haemopexin concentration.

\section{Results}

INDEX PATIENTS AND SECONDARY CASES

Nine patients had died at the beginning of the study and five died during the 3 years of the study. The ages of the living patients and the ages at death of those who had died are given in table 2. The ages at which they had presented on account of muscle weakness (usually as a difficulty in walking noticed by their parents) ranged from 6 months to 6 years, with a modal onset of 1 to 2 years and a mean onset age of 2.4 years. However, the mean age at diagnosis was $5 \cdot 7$ years.

Of the 41 boys who had reached the age of 8 , $13(0 \cdot 31)$ were already chairbound, as were $23(0 \cdot 67)$ of the 34 who had reached the age of 10 , and all of the 28 boys who had reached the age of 12 . Mental retardation (usually mild) was evident in $27(0 \cdot 6)$ of 45 boys and was not related to the age of onset of symptoms or to the progress of the disease. Four index patients presented on account of severe mental retardation before muscle weakness became apparent, and in two of these the diagnosis was delayed until 8 and 11 years.

In the 54 families no parent was affected and there

TABLE 2 Ages of patients and their brothers when seen (with ages at death of those who died in parentheses)

\begin{tabular}{|c|c|c|c|c|c|c|c|c|c|}
\hline & $0-1$ & $2-3$ & $4-5$ & $6-7$ & $8-9$ & $10-11$ & $12-15$ & $16-20$ & Over 20 \\
\hline $\begin{array}{l}\text { Index patients (54) } \\
\text { Affected brothers (13) } \\
\text { Unaffected brothers (42) }\end{array}$ & $\begin{array}{l}0 \\
0 \\
0(2)\end{array}$ & $\begin{array}{l}1 \\
0 \\
2 *\end{array}$ & $\begin{array}{l}2 \\
1 \\
1\end{array}$ & $\begin{array}{r}10 \\
1 \\
2\end{array}$ & $\begin{array}{l}7 \\
1 \\
3\end{array}$ & $\begin{array}{l}6 \\
3 *(1) \\
5\end{array}$ & $\begin{array}{l}12(4) \\
3^{*}(2) \\
10\end{array}$ & $3^{1(7)}$ & $\begin{array}{c}1(3) \\
0 \\
14\end{array}$ \\
\hline
\end{tabular}

*Includes one pair of monozygotic twins. 
was no instance of consanguinity. There was a total of 127 liveborn sibs, of whom 70 were full sisters, two were half sisters, 51 were full brothers, and four were half brothers. Fifty-nine sibs ( 31 sisters and 28 brothers) were born after the index patient and of these 44 (22 sisters and 22 brothers) were born before the diagnosis had been made. The ages of the brothers are shown in table 2. Thirteen brothers had Duchenne muscular dystrophy and they included two pairs of similarly affected monozygotic twins. Of the 42 unaffected brothers, two were premature twins who died soon after birth and two were monozygotic twins aged 2 years who were clinically healthy and had normal levels of creatine kinase. The other six reputedly unaffected boys under the age of 10 appeared healthy on examination and it is most unlikely that any will later develop signs of muscular dystrophy. If the three pairs of monozygotic twins are counted as one brother each, and the twins who died in infancy excluded, the incidence of affected brothers is 11 out of $50(22 \%)$. The incidence of affected brothers born after the index patient but before the diagnosis was made in him (that is, before knowledge of the disorder could have affected family size) was five out of $22(23 \%)$.

There were 31 male relatives other than brothers who had Duchenne muscular dystrophy in these families and in all instances inheritance was consistent with $X$ linkage. In eight families there were affected males in two generations, in three families in three generations, and in one family in four generations. Seven index patients had affected brothers but no other affected relatives and 35 index patients were isolated cases. No intrafamilial similarity with regard to severity or presence of mental retardation was evident in the four pairs of affected living brothers.

\section{INCIDENCE OF DUCHENNE MUSCULAR} DYSTROPHY

It proved impossible to ascertain all cases in the whole of the West Midlands and so the incidence study was confined to the city of Birmingham. It was considered that the best ascertainment occurred in children of school age, since half the patients were not diagnosed until they went to school, and since all those who ultimately need special education in physically handicapped schools would be recognised. The city of Birmingham publishes statistics ${ }^{8}$ on the numbers of children attending schools including special schools. In 1976 there were 110434 boys attending Birmingham schools. The number of cases of Duchenne muscular dystrophy who were then known to us, who lived within the city, and who were aged 5 to 16 years, was 23 . These included three boys who died before 1976, but who would have been at school that year had they survived. The 23 boys comprised 16 index patients, two secondary cases, and five patients for whom permission to study was refused.

During 1979 and 1980 a fresh search for patients with Duchenne muscular dystrophy was made and four further cases were found, who were aged 5 or over in 1976. This brings the total number of affected boys to 27. The prevalence of Duchenne muscular dystrophy among boys aged 5 to 16 within the city of Birmingham was therefore 1 in 4090 in 1976.

\section{EVALUATION OF TESTS FOR PREDICTING CARRIERS \\ Tests on obligatory heterozygotes}

There were 27 obligatory heterozygotes in the study who came from 19 families and were aged 26 to 72 years with a mean of 43.9. They consisted of 19 mothers, two grandmothers, two aunts, one greatgrandmother, and three great-aunts. The distribution in them of muscular symptoms and signs is shown in table 3 . Of the seven women who had enlargement or weakness of muscles, six had raised CK levels.

The distributions of $\mathrm{CK}$ levels performed in the two laboratories are displayed graphically in figs 1 and 2. There was greater overlap between heterozygotes and controls on QEMC data, and the coefficient of variation was greater (fig 2). Thus, there was a greater distinction between controls and obligatory heterozygotes on the MCNN data, where 18 of $27(0.66)$ obligatory heterozygotes had CK levels above $2 \mathrm{SD}$ for the controls. In comparison,

TABLE 3 Symptoms and signs in four groups of female relatives

\begin{tabular}{|c|c|c|c|c|}
\hline & Symtoms of weakness & Signs of weakness & Large calves & No symptoms or signs \\
\hline $\begin{array}{l}27 \text { obligatory heterozygotes } \\
40 \text { daughters of obligatory heterozygotes } \\
34 \text { mothers of isolated cases } \\
35 \text { sisters of isolated cases }\end{array}$ & $\begin{array}{l}2(1)^{*} \\
3(2) \\
3(2) \\
2\end{array}$ & $\begin{array}{l}2(2) \\
3(3) \\
5(3 \dagger) \\
3(2)\end{array}$ & $\begin{array}{l}6(6) \\
5(5) \\
9(5) \\
3(2)\end{array}$ & $\begin{array}{l}20(11) \\
32(13) \\
23(8) \\
30(3 \ddagger)\end{array}$ \\
\hline
\end{tabular}

*The numbers in parentheses refer to those women with CK levels above 2 SD for their appropriate control group.

†One was attending a neurologist on account of her marked weakness.

¥One had a mean CK level of 1995 IU/1. 


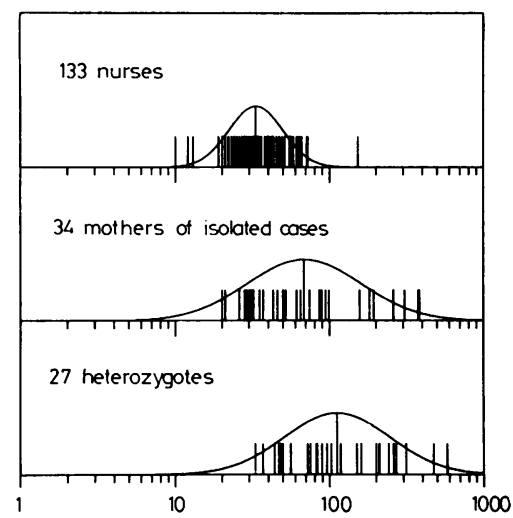

FIG 1 MCNN results showing the distribution of mean levels of creatine kinase in controls (top), mothers of isolated cases (middle), and obligatory heterozygotes (bottom).

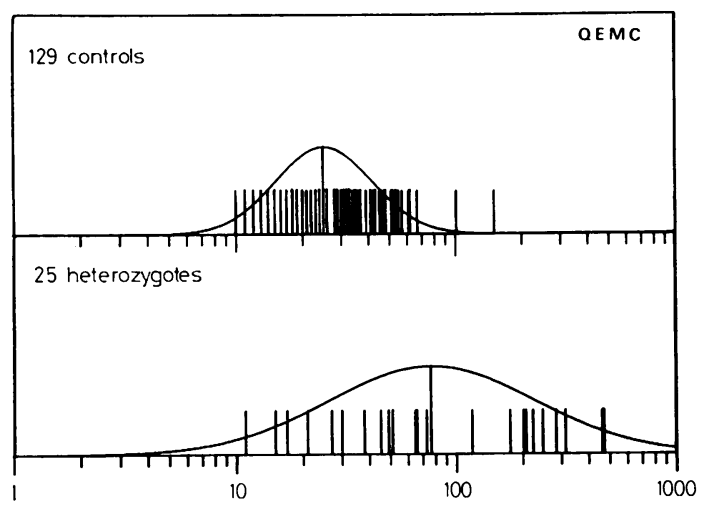

FIG 2 QEMC results showing the distribution of mean levels of creatine kinase in controls (top) and in obligatory heterozygotes (bottom)

only 11 of $25(0 \cdot 44)$ of the obligatory heterozygotes tested at QEMC had levels above 2 SD for the controls. For these reasons MCNN data only have been used for subsequent analysis.

If we assume that the logarithms of the CK values for obligatory heterozygotes and controls are Normally distributed, then direct comparison can be made between the two groups for the purpose of estimating the likelihood that a female of unknown status is a carrier. ${ }^{9}$ These odds have been calculated for different CK levels using the present data. ${ }^{10}$

Haemopexin levels were measured in 12 heterozygotes and compared to the levels in 14 controls. The respective means were 1.06 and $1.058 \mathrm{~g} / \mathrm{l}$; the quoted range of normality for the method was
0.5 to $1 \cdot 15 \mathrm{~g} / \mathrm{l}$. Because of the lack of any difference between the two groups, haemopexin levels were not measured on women who were possible carriers.

\section{Tests on possible carriers}

The overall incidence of muscular symptoms or signs in possible carriers was 24 in $109(0 \cdot 22)$ compared to the incidence in obligatory heterozygotes of 7 in $20(0.35)$ (table 3). Most of these women had raised CK levels. It was felt that the clinical assessment of large calves was too subjective to be used as an indicator for the carrier state in the absence of a raised CK level. The incidence of symptoms or signs in relatives of females who had symptoms or signs (counting each family once only and excluding the index female with signs) was 9 in 37 or $0 \cdot 24$, not significantly different from the overall incidence.

Fig 1 shows the distribution of CK levels in 34 mothers of isolated cases; the mean is lower than that for the heterozygotes and the standard deviation is greater, which together suggest the presence of two classes of women. Table 4 gives the numbers of female relatives in different groups who have mean CK levels above 2 SD for appropriately aged controls. Data on girls of 11 or under are excluded since controls were not available.

PARENTAL AGE AND NEW MUTATIONS Of the 35 isolated cases, the mothers of 21 had normal CK levels, as did all other female relatives who were tested. Pedigree analysis incorporating the numbers of unaffected male relatives in these 21 families shows that over $80 \%$ of these boys are likely to be new mutants. The mean age of their

TABLE 4 The numbers of carriers detected by $C K$ testing (proportions are in parentheses)

\begin{tabular}{|c|c|c|}
\hline Group & $\begin{array}{l}\text { Observed numbers } \\
\text { with CK levels above } \\
2 S D \ddagger \text { for appropriately } \\
\text { aged controls } \\
\text { (MCNN data) }\end{array}$ & $\begin{array}{l}\text { Estimated numbers } \\
\text { of carriers if } 0 \cdot 34 \\
\text { have normal CK } \\
\text { levels }\end{array}$ \\
\hline \multirow{7}{*}{$\begin{array}{l}27 \text { obligatory } \\
\text { heterozygotes } \\
24 \text { daughters* of } \\
\text { obligatory } \\
\text { heterozygotest } \\
53 \text { mothers of all } \\
\text { index patients } \\
34 \text { mothers of } \\
\text { isolated cases } \\
22 \text { sisters* of } \\
\text { isolated cases } \\
12 \text { grandmothers of } \\
\text { isolated cases } \\
24 \text { aunts of } \\
\text { isolated cases }\end{array}$} & $18(0.66)$ & $27(1 \cdot 0)$ \\
\hline & $10(0.42)$ & $15(0.62)$ \\
\hline & $24(0.45)$ & $36(0 \cdot 68)$ \\
\hline & $13(0.38)$ & $20(0.59)$ \\
\hline & $4(0 \cdot 18)$ & $6(0 \cdot 27)$ \\
\hline & $2(0 \cdot 17)$ & $3(0.25)$ \\
\hline & $1(0.04)$ & $1-2(0.06)$ \\
\hline
\end{tabular}

* Excluding those aged under 12.

tI have excluded those daughters whose sons were responsible for their mother being identified as an obligatory heterozygote. †Standard deviations were based on logged values. 
mothers at the birth of their affected son was 25.9 years. The mean maternal age in England and Wales between 1962 and 1966 was $27 \cdot 3$ years.

There were 16 mothers considered to be carriers because they had two affected sons (six mothers), or one affected son and a daughter with a high mean CK level (five mothers), or had high levels of CK themselves (five mothers), and in whose families there were no affected males or carrier females in an earlier generation, and the numbers of unaffected males made it unlikely that the grandmother was a carrier. Pedigree analysis showed that fewer than 1 in $\mathbf{8}$ of the grandmothers were likely to be carriers. The mean paternal age at the birth of these 16 women was 30.6 years and the mean maternal age was 28.6 years. The Registrar General's figures for the 1931 census give a mean paternal age of 32.0 years and a mean maternal age of $29 \cdot 8$ years.

\section{GENETIC COUNSELLING}

Of these 54 families there were only nine with no female relative in need of genetic counselling. In the remaining families there was a total of 142 female relatives who were aged under 40 and who had a risk (based on pedigree analysis) of 1 in 10 or greater of being a carrier. Of these, $66(0.46)$ were aged 15 years or less. These figures show the need for genetic counselling.

However, before the study, genetic counselling had had little effect on the size of the patients' sibship. Two observations bear this out. Firstly, the 24 mothers who had raised levels of CK had similar numbers of children born after the index patient as did those 29 mothers who had normal levels of CK: 24 further children (of whom six were affected) compared to 31 further children (of whom one was affected). Secondly, the proportion of affected brothers born after the index patient, but before the diagnosis was made in him, was similar to the proportion of affected brothers in the whole study (see above).

Genetic counselling is, however, affecting the young members of these families, in particular the sisters of patients. This is indicated by the currently increasing number of requests for genetic counselling for young girls at risk and by the fact that the present study showed a greater co-operation from families in whom there were sisters: the index patients had 72 sisters compared to 55 brothers.

Seventeen women became pregnant during the study: four mothers, eight sisters, three aunts, and two cousins. Of these, eight were given a low risk of having an affected son (1 in 20 or lower); these women continued with their pregnancies. Three healthy sons and five healthy daughters have been born. Nine women were given a high risk for having an affected son ( 1 in 6 or worse) and were offered prenatal fetal sexing. Three had a termination of pregnancy without fetal sexing; two of the abortuses were known to be male. Five women had an amniocentesis. Three were found to be carrying females and proceeded with their pregnancies and two were carrying males, of whom one had a therapeutic abortion and the other decided to continue with the pregnancy and has since had a healthy son with a normal CK level. One woman refused both amniocentesis or abortion, as did another whose two affected sons were not included as index patients on account of maternal anxiety. The first of these women has had a boy whose CK level is over 7000 units and the second had a healthy girl.

\section{Discussion}

Ascertainment of cases for this study was considered to be independent of the presence or absence of an affected male relative. It was thought to be reasonably complete for the city of Birmingham, since an opportunity was given three years later for further ascertainment of cases. The incidence of 1 in 4000 for the city of Birmingham is similar to that found elsewhere. ${ }^{11}$

The incidence of Duchenne muscular dystrophy among brothers of index patients was $0 \cdot 22$. This observation is similar to that of other unselected studies, ${ }^{2-6}$ and suggests that half the mothers of index patients are carriers. If this is so, then mutation must be commoner in females than in males, and perhaps occurs exclusively in females. This question is discussed in detail elsewhere. ${ }^{10}$

No clinical evidence for genetic heterogeneity was observed in the few families where there was more than one affected living male.

Three methods were assessed for their possible usefulness in the detection of carriers. Of these, the level of haemopexin was of no value as the results in controls and obligatory heterozygotes were essentially identical. It was considered that the assessment of large calves was too subjective to be used predictively, but that muscle weakness, when present, is a useful sign of the carrier state, but its absence is not helpful. Unlike Moser and Emery, ${ }^{12}$ the study did not show a higher incidence of muscle weakness among female relatives of a carrier with signs.

The use of creatine kinase in giving a probability that a woman is a carrier for Duchenne muscular dystrophy has been discussed elsewhere. ${ }^{13} 14$ Similar results were obtained in this study, and an odds table has been calculated and is now distributed with every CK estimation performed for the detection of 
carriers, with the warning that pedigree data should be incorporated into the final assessment.

The distribution of $\mathrm{CK}$ levels in mothers of isolated cases suggests that about one half of them are carriers, and that about two-thirds of all mothers are carriers (fig 1, table 4). Although this is similar to other studies, ${ }^{15-18}$ it conflicts with the previously mentioned observation that only one quarter of brothers of index patients are affected. The sex ratio among sibs of index patients was equal in those studies where there was no ascertainment bias in favour of patients with sisters, ${ }^{2-46}$ so the smaller than expected proportion of affected males lis not explained by loss of affected male fetuses. Further statistical evidence bearing on this conflict may be found elsewhere. ${ }^{10}$

There appears to be no increased parental age effect for those subjects believed to be carrying a new mutation. This was also the conclusion of Blyth and Pugh, ${ }^{4}$ but in contrast Emery ${ }^{11}$ considered that there was an increase in mother's father's age, if the mother was a new mutation. Our findings do not show this.

It was interesting that any previous genetic advice had had little effect on the size of the index patient's sibship, but that genetic counselling is being welcomed for the present generation. However, some women had not received genetic advice before becoming pregnant, which made a decision difficult for them. This was partly because of delayed diagnosis of the index patient, and a plea has been made for the prompt diagnosis in a boy who is walking late or poorly. ${ }^{19}{ }^{20}$ In this study five affected brothers had been born before the diagnosis had been made in the index patient. An additional reason for the delay in giving genetic advice was a failure to search for and advise female relatives at risk. This would be a large task, as is shown by the numbers of females at risk. Of particular note are the 66 who were aged under 16 and who will need an offer of genetic counselling some years hence. In order to assist such a follow-up service, a genetic register would be useful so that contact may be maintained with the families of patients. Such an active register is well established in Edinburgh. ${ }^{21}$

Probably some explanation of genetic risks should be made to girls early in their life, so that they are not surprised by them later, but these risks should be more accurately assessed when they are in their late teens. The problem of whether or not to give genetic advice on the basis of CK levels to teenage girls has been discussed by several workers. For example, Nicholson $e a^{22}$ have suggested that discrimination between carriers and non-carriers might be best in teenagers. However, proof of this is not yet existent and in the meantime it is probably best to be cautious about the interpretation of CK levels in girls under $\stackrel{\mathbb{P}}{+}$ the age of $16 .{ }^{7}$ Further data with follow-up studies is $\underset{\vec{D}}{\vec{D}}$ necessary to resolve the issue.

I am grateful to Professor J H Edwards for initiating $\frac{\bar{\rho}}{\bar{D}}$ the study, for his supervision and advice, and for the $\stackrel{\mathbb{Q}}{\square}$ statistical analysis of the CK distributions. I thank क Dr J Insley for his help and support and the paedia- $\vec{\circ}$ tricians and neurologists in the West Midlands who referred patients. I thank Mrs J M Crawley for $\vec{\omega}$ performing the haemopexin estimations and the CK estimations at QEMC, and I thank Mr R A Westhead and Dr S Hickey for performing CK estima- $\vec{\oplus}$ tions at MCNN. I am grateful to the Muscular Dystrophy Group of Great Britain for financial $\overrightarrow{-}$ support for this study.

\section{References}

1 Gardner-Medwin D. Mutation rate in Duchenne type of muscular dystrophy. J Med Genet 1970;7:334-7.

2 Stephens FE, Tyler FH. Studies in disorders of muscle. Am J Hum Genet 1951;3:111-25.

3 Stevenson AC. Muscular dystrophy in Northern Ireland. Ann Hum Genet 1953;18:50-93, 1955;19:159-64, 1958;22: 231-4.

4 Blyth H, Pugh RJ. Muscular dystrophy in childhood. The genetic aspect. Ann Hum Genet 1958;23:127-63.

5 Thompson MW, Hutton EM. The occurrence of new mutants in $\mathrm{X}$-linked recessive lethal disorders. In: $\mathbb{Q}$ Armenclares S, Lisker R, eds. Abstracts $V$ International $\overrightarrow{\vec{T}}$ Congress of Human Genetics. Amsterdam: Excerpta 윽 Medica, 1976:195.

6 Zatz M, Lange K, Spence MA. Frequency of Duchenne müscular dystrophy carriers. Letter. Lancet 1977;i:759.

7 Bundey S, Crawley JM, Edwards JH, Westhead RA. Serum creatine kinase levels in pubertal, mature, pregnant, and postmenopausal women. $J$ Med Genet 1979;16:11721 .

8 West Midlands County Council. Central statistical information and research unit. Annual statistical abstract, §ᄋ 1977.

9 Dennis NR, Carter CO. Use of overlapping normal distributions in genetic counselling. J Med Genet 1978; 15:106-8.

10 Edwards JH, Bundey S. Evidence that new mutations for Duchenne muscular dystrophy occur predominantly in females (in preparation).

11 Emery AEH. Genetic considerations in the X-linked muscular dystrophies. In: Rowland LP, ed. Pathogenesis $\mathrm{N}$ of human muscular dystrophies. Amsterdam: Excerpta N Medica, 1977.

12 Moser H, Emery AEH. The manifesting carrier in Duchenne muscular dystrophy. Clin Genet 1974;5:271-84. 0

13 Wilson KM, Evans KA, Carter CO. Creatine kinase levels in women who carry genes for three types of muscular dystrophy. Br Med J $1965 ; \mathrm{i}: 750-3$.

14 Emery AEH. Genetic counselling in X-linked muscular dystrophy. J Neurol Sci 1969;8:579-87.

15 Thompson MW, Murphy EG, McAlpine PJ. An assessment ${ }^{\circ}$ of the creatine kinase test in the detection of carriers of Duchenne muscular dystrophy. J Pediatr 1967;71: 82-93. 
16 Zatz M, Froto-Pessoa O, Levy JA, Peres CA. Creatine phosphokinase (CPK) activity in relatives of patients with $\mathrm{X}$-linked muscular dystrophies: a Brazilian study. J Genet Hum 1976;24:153-68.

17 Davie AM, Emery AEH. Estimation of proportion of new mutants among cases of Duchenne muscular dystrophy. J Med Genet $1978 ; 15: 339-45$.

18 Sibert JR, Harper PS, Thompson RJ, Newcombe RG. Carrier detection in Duchenne muscular dystrophy. Arch Dis Child 1979;54:534-7.

19 Siegel IM. Very early diagnosis of Duchenne muscular dystrophy. Letter. Lancet 1976;ii:90.

20 Gardner-Medwin D, Bundey S, Green S. Early diagnosis of Duchenne muscular dystrophy. Letter. Lancet 1978;i : 1102.
21 Emery AEH. RAPID: a genetic register system for the ascertainment and prevention of inherited disease. In: Emery AEH, Miller JR, eds. Registers for the detection and prevention of genetic disease. Miami: Symposia Specialists, 1976.

22 Nicholson GA, Gardner-Medwin D, Pennington RTJ, Walton JN. Carrier detection in Duchenne muscular dystrophy; assessment of the effect of age on detectionrate with serum creatine kinase activity. Lancet $1979 ; \mathbf{i}$ : 692-4.

Requests for reprints to Dr Sarah Bundey, Department of Clinical Genetics, Infant Development Unit, Queen Elizabeth Medical Centre, Edgbaston, Birmingham B15 2TG. 